\title{
A Case Study of Self-regulated English Learning Capability of Undergraduates from Open University of China
}

\author{
Yuanyuan Fan', a, Yuheng Wang ${ }^{2, b}$ \\ ${ }^{1}$ School of Foreign Languages, Jilin Agricultural University, Changchun 130118, China \\ ${ }^{2}$ School of Foreign Languages, Changchun Radio and TV University, Changchun 130051, China \\ aeastwindyuan@163.com, b9746692@qq.com
}

Keywords: Self-Regulated Learning; English Courses; Learning Styles; Pedagogical Strategies.

\begin{abstract}
Second language (L2) Learners' beliefs about English have become one of important factors to influence their self-regulated learning capacities and achievements. This exploratory study investigated L2 learners' style preferences of learning English in distance education programs based on the results of 186 pieces of questionnaires retrieved. Statistical analyses of questionnaires show that L2 learners don't have adequate self-regulated learning capabilities with reference to learning motivation, learning attitudes, strategy use and self-assessment though they accept the open education context well, which may contribute to the development of pedagogical strategies to improve students' learning efficacy at the Open University of China.
\end{abstract}

\section{Introduction}

Research on self-regulated learning has been the focus of much attention from linguists and educational researchers in China since 1980s. The capacities of self-regulated learning for second language (L2) learners include the formulation of goals, the determination of content and procedures, the choice of learning strategies, and the will of cooperation (Cai 2004). To promote these capacities is considered as one of educational targets that motivate learners to initiate, develop and continue self-regulated learning processes and behaviors ( $\mathrm{Fu} 2009)$. Thus, the importance of self is highlighted in second language learning.

At present, many researchers have explored self-regulated learning in the respects of framework, characteristics and practices (Guo \& Dai 2011), but there is little attention paid to the self-regulation capabilities of L2 learners at the Open University of China. The aim of this paper is to study L2 learners' style preferences of learning English in an open higher educational context.

\section{Literature Review}

In recent years, a considerable amount of literature has been published on self-regulated learning. The understanding of this concept mainly reflects three schools of thought such as learning styles, metacognition and regulation styles, and theories of the self (Wang 2002). Holec (1981) employs "autonomy" to account for the capabilities that the learners are responsible for achieving academic goals.

Self-regulated learning in this study refers to learning styles that L2 learners would like to adopt in distance education programs. The learner's style preferences are characterized by the attitude of learning, the use of strategies and the education context in the process of acquiring English (Wang 2002). The three features integrate with each other. The promotion of learners' capabilities can't be achieved without the context as teachers' instruction plays a vital role in enhancing self-regulation (Xu, Peng \&Wu 2004).

Although considerable research has been devoted to self-regulated learning, few studies have been conducted to investigate L2 learners in open education context. These learner's style preferences may be different from others' from universities due to various education background. Therefore, we 
initiate exploration into a group of learners from Changchun Campus of the Open University of China through questionnaires to improve their self-regulated learning abilities and English performance.

\section{Methodology}

This research was conducted on Changchun Campus of the Open University of China. The participants consisted of 210 non-English major undergraduates enrolled in the spring of 2015. In this survey, they were asked to agree or disagree with statements on a scale of 'Strongly disagree' with 'Strongly agree'. The use of the Likert scale survey statements helps us to obtain similar information to the open-ended response questions.

We adopted the format of questionnaires designed by Xu, Peng and $\mathrm{Wu}$ (2004), covering learning motivation, the use of strategies, self-assessment, attitudes and education context. Items of questionnaires were modified to adapt to the characteristics of open education. The credibility and validity of questions were also examined.

\section{Results and discussion}

This questionnaire survey aims to investigate L2 learner's regulated-learning style preferences in acquiring English. Of 210 questionnaires sent, 186 valid questionnaires retrieved, meaning a participation rate of $88.6 \%$. The results of the survey are shown as follows.

Table 1. The descriptive statistics of five factors of L2 Undergraduates' regulated-learning style preferences $(\mathrm{N}=186)$

\begin{tabular}{|c|c|c|}
\hline Factors & Mean $(\mathrm{M})$ & Standard Deviation (SD) \\
\hline Learning motivation & 2.324 & 1.151 \\
\hline Learning attitude & 2.173 & 1.093 \\
\hline Learning strategy use & 2.125 & 0.997 \\
\hline Self-assessment & 2.086 & 0.938 \\
\hline Education context & 3.783 & 0.922 \\
\hline
\end{tabular}

As can be seen from the above table, the descriptive statistics of five factors of L2 Undergraduates' regulated-learning style preferences indicate that no significant differences are found among five variables despite the differences in data.

The mean value of education context $(M=3.783)$ is highest, showing that the open distance education program has been well accepted. Most participants ( $\mathrm{SD}=0.922)$ approved that the context had positive effects on the process of self-learning. However, the mean value is observed low in learning motivation $(M=2.324)$, followed by learning attitudes $(M=2.173)$, strategies use $(M=2.125)$ and self-assessment $(\mathrm{M}=2.086)$. The data demonstrated that participants exhibited a deficiency in self-regulated learning capabilities although they had potential to study English by themselves. Their learning motivation $(\mathrm{SD}=1.151)$ and attitudes $(\mathrm{SD}=1.093)$ varied greatly as they came from different education backgrounds. There are no significant differences among individuals concerning self-assessment $(\mathrm{SD}=0.938)$ and strategies use $(\mathrm{SD}=0.997)$.

The result of the case study suggests that to improve L2 learners' self-regulated learning capabilities is a necessity. Strategy teaching is found as an effective approach that may help learners form their own appropriate learning style. Teachers might introduce strategies to settle practical problems encountered by students in the process of learning English, followed by a series of relative tasks designed cautiously. To accomplish these activities and ensure efficiency, the control of teaching rhythm seems to be obviously essential. Therefore, modern education technology such as Massive Open Online Resources (MOOC) and microlectures has been explored to meet the demand of the Open University. Take microlectures for example. This multi-media method offers learners an easy avenue to engage individually with strategy learning activities as their academic achievements rely on engagement. On the stage of evaluation, teachers also shoulder the responsibilities of 
providing effective feedback through web learning platforms, motivating learners to identify the gaps in learning strategies and regulate their performance.

In the present study, most participants had a difficulty in appraising their own performance accurately. This finding indeed shows that to develop learners' self-assessment skills is a key for autonomous language learning. When students can't perceive any clear progress, they may be less active and focused. Teachers may enact formative assessment practices to help students learn what they have achieved in the middle of teaching and learning processes. Thus, students will be better placed to monitor their progress and promote a sense of agency in learning.

Additionally, the result of the research indicates that participants differ significantly in their learning motivation and attitudes. The strategy for increasing student motivation is to establish a learner-centered context. Teachers may understand and respect each learner by setting mastery and relative goals, which is crucial for the development of persistence, attention and goal specificity. In this way, students might be motivated to realize their roles as creative agents responsible for their own learning and have confidence in reaching goals. Teachers may organize group discussion on web and ask students to write self-reflection essays, contributing to a well-rounded learning plan to enhance their self-regulation capabilities in second language acquisition.

\section{Conclusion}

This case study presents a clear picture of L2 learners' style preferences of learning English, pointing to the reasonable determinants of their academic achievements in the distance education programs. The participants in the survey exhibit inadequate abilities with references to learning motivation, learning attitude, strategy use and self-assessment though the education context is highly evaluated. The knowledge of style preferences may provide teachers with an insight into the best-suited programs that help students who have various learning style. The integration of leaner-centered perspective, strategy training, formative assessment and instruction tech is proposed as an attempt to construct supportive and encouraging environments of learning English both for teachers and students.

This research has implications for the construction of self-regulated learning model since self-regulated learning capabilities is the key to improving students' academic achievements especially for the Open University of China. The understanding of their capabilities of learning English may be the first step to break down barriers in practice. However, this questionnaire survey is limited to the size of investigation. More empirical studies are needed to explore self-regulated learning in order to maximize high standards of motivation and achievements for all learners in open education context.

\section{References}

[1]. Cai, J. G. On the basic principles of the teaching requirement for college English. Foreign Languages and Their Teaching 1 (2004):17-20.

[2]. Fu, L.F. An evaluation model of college English teaching under network environment. Journal of Jiangxi Normal University (Philosophy and Social Sciences Edition) 3 (2009): 36-38.

[3]. Guo, J.R. \& Dai, W. D. An empirical study on evaluation of college students' learner autonomy in English learning. Foreign Language World 6 (2011): 79-87.

[4]. Holec, H. Autonomy and foreign language learning. Strasbourg: Council of Europe, 1979.

[5]. Wang, D. Q. Fostering learner autonomy in college English study. Foreign Language World 5(2002): 17-23.

[6]. Xu, J. F., R. Z. Peng, and W. P. Wu. Survey and analysis on college non-English majors' autonomous English learning ability. Foreign Language Teaching and Research 36.1 (2004): 64-68. 